\title{
Suzuki-Miyaura Reaction with NHC-Cu-Pd MOF Catalysts
}

Polymer-Supported

Synthesis

Key words

N-heterocyclic carbenes

palladium

cross-coupling

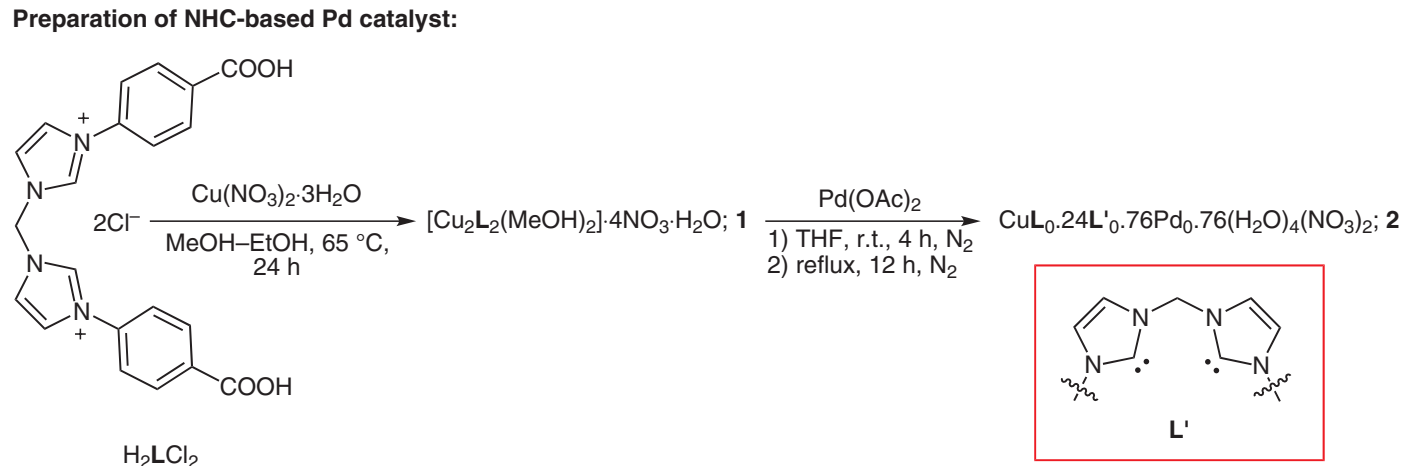

Suzuki-Miyaura reaction:

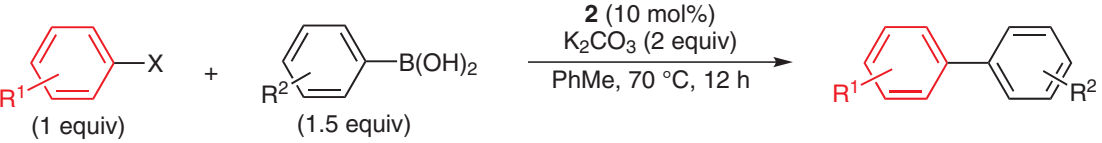

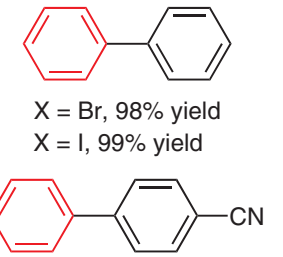

$\mathrm{X}=\mathrm{Br}, 3.4 \%$ yield

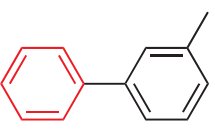

$\mathrm{X}=\mathrm{Br}, 93 \%$ yield

$X=1,97 \%$ yield

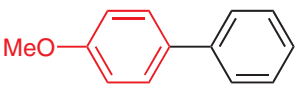

$\mathrm{X}=\mathrm{Br}, 81 \%$ yield $\mathrm{X}=\mathrm{I}, 91 \%$ yield

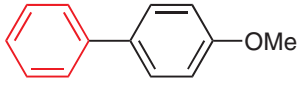

$\mathrm{X}=\mathrm{Br}, 91 \%$ yield $X=I, 95 \%$ yield

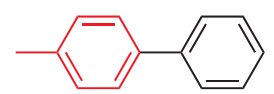

$\mathrm{X}=\mathrm{Br}, 84 \%$ yield

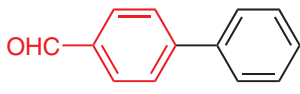

$\mathrm{X}=\mathrm{Br},>99 \%$ yield

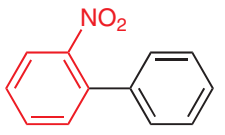

$\mathrm{X}=\mathrm{Br}, 99 \%$ yield
Significance: A metal-organic framework (MOF) catalyst 2 was prepared from dicarboxylic acid $\mathrm{H}_{2} \mathbf{L} \mathrm{Cl}_{2}$ bearing two azolium components through the MOF formation with $\mathrm{Cu}\left(\mathrm{NO}_{3}\right)_{2} \cdot 3 \mathrm{H}_{2} \mathrm{O}$ followed by the modification with $\mathrm{Pd}(\mathrm{OAc})_{2}$. The SuzukiMiyaura reaction of aryl halides and arylboronic acids was carried out with 2 (10 mol\%) in toluene to give the corresponding biaryl products in 81$99 \%$ yield.
Comment: MOF catalyst 2 was recovered by filtration and reused five times without loss of catalytic activity. A catalyst prepared from $\mathrm{H}_{2} \mathbf{L} \mathrm{Cl}_{2}$, $\mathrm{CuCl}_{2}$, and $\mathrm{Pd}(\mathrm{OAc})_{2}$, which has a different MOF structure, exhibited much lower catalytic activity (4-methoxybiphenyl: 43\%) than 2, highlighting the important roles of the framework structures in determining the catalytic performance. 